Foro Interno. Anuario de Teoría Política

ISSN: 1578-4576

\title{
Nudo borromeo y teoría del discurso. Contribuciones para el análisis de identidades, fenómenos y procesos políticos y sociales ${ }^{1}$
}

\author{
Hernán Fair ${ }^{2}$
}

Recibido: 22 de febrero de 2021 /Aceptado: 28 de abril de 2021

Resumen. Este trabajo explora algunos usos innovadores de la figura del nudo borromeo de la teoría lacaniana con el objetivo de complejizar y fortalecer la investigación social desde el Análisis Político del Discurso. En la primera parte: (a) se distinguen tres modalidades discursivas de anudamiento borromeico que entrelazan lo Real, lo Simbólico y lo Imaginario a nivel espacial y temporal; (b) se distingue entre los tipos de anudamientos, su extensión, su intensidad y su tiempo de estructuración y sedimentación social; (c) se analiza la dinámica discursiva de (des)anudamiento borromeico entre Real, Simbólico e Imaginario, a través de los modos de identificación imaginarios en las fantasías ideológicas, los acontecimientos fuertemente dislocadores y los síntomas que simbolizan lo Real mediante el orden significante. En la segunda parte, se proponen algunas estrategias analíticas útiles para el estudio de identidades, fenómenos y procesos políticos y sociales y se ilustra con algunos ejemplos. En la última parte, se examinan las implicancias epistemológicas y axiológicas del uso de esta herramienta lacaniana para fortalecer la investigación social crítica desde la Teoría Política del Discurso.

Palabras clave: Nudo borromeo; anudamientos entre Real, Simbólico e Imaginario; fantasía ideológica; síntoma; teoría lacaniana.

\section{[en] The Borromean Knot and Discourse Theory. Proposals for the Analysis of Identities, Phenomena and Sociopolitical Processes}

\begin{abstract}
This paper explores innovative uses of the figure of the Borromean knot in lacanian theory with the aim of strengthening social research from a political discourse analysis approach. The first part of this paper: (a) distinguishes three discursive modalities of Borromean knot that intertwine the Real, the Symbolic and the Imaginary at a spatial and temporal level; (b) distinguishes between types of knotting, their extension, intensity and time of structuring and social sedimentation; (c) analyses the dynamic of Borromean (un) knotting of the Real, Symbolic and Imaginary, through imaginary modes of identification in ideological fantasies, deeply dislocating events, and symptoms that symbolize the Real through the significant order. In the second part, several useful analytical strategies for the study of identities, phenomena and sociopolitical processes are proposed and illustrated with examples. In the last part, the epistemological and axiological implications of the use of this lacanian tool to strengthen critical social research from the Political Theory of Discourse are examined.
\end{abstract}

Keywords: Borromean knot; knotting between Real, Symbolic and Imaginary; ideological fantasy; symptom; lacanian theory.

Sumario: 1. Introducción. 2. Breves consideraciones teóricas sobre las herramientas lacanianas y sus usos en la investigación social. 2.1. El nudo borromeo en la teoría de Jacques Lacan. 3. Usos del nudo borromeo en la teoría del discurso y las identidades políticas. 4. Tres modalidades de anudamiento borromeico de lo social. 4.1. Anudamientos contingentes y de mutua imbricación. 4.2. Anudamientos esencialistas-perversos. 4.3. Pseudo anudamientos esencialistas-psicóticos. 5. Modos, tipos, tiempos e intensidades de entrelazamiento borromeico entre los elementos del sistema. 5.1. Tipos de anudamientos. 5.2. Extensión o longitud del anudamiento. 5.3. Intensidad o fuerza del anudamiento. 5.4. Tiempo de sedimentación del anudamiento. 6. El nudo como metáfora del entrelazamiento entre las dimensiones, planos y registros de lo social. 7. Usos del nudo borromeo para el análisis discursivo de identidades, fenómenos y procesos políticos y sociales. 7.1. El nudo borromeo en el análisis de las fantasías ideológicas que simbolizan e intentan atrapar a lo Real. 7.2. Los límites históricos de la fantasía ideológica: el nudo borromeo en el análisis de los síntomas que simbolizan lo Real en la dinámica política. 7.2.1. Inhibición, resignación y apatía política (respuesta pasiva). 7.2.2. Reactivación y acción política (respuesta activa). 7.3. Los modos de simbolizar sintomáticamente lo Real en los acontecimientos históricos catastróficos. 8. Algunas estrategias analíticas útiles para la investigación social. 9. A modo de conclusión. 10. Referencias bibliográficas.

Cómo citar: Hernán Fair, "Nudo borromeo y teoría del discurso. Contribuciones para el análisis de identidades, fenómenos y procesos políticos y sociales”: Foro Interno. Anuario de Teoría Política, vol. 21 (2021), pp. 17-32.

Este trabajo es patrocinado y cuenta con el respaldo del Consejo Nacional de Investigaciones Científicas y Técnicas (CONICET).

Universidad Nacional de Quilmes/CONICET (República Argentina)

E-mail: hernan.fair@unq.edu.ar

Foro interno 21 2021: 17-32 


\section{Introducción}

El presente trabajo se propone como objetivo general examinar algunas herramientas complejas de la teoría lacaniana para fortalecer el Análisis Político del Discurso (APD) en la investigación social. Los objetivos específicos consisten en: (1) Explorar los usos de la figura del nudo borromeo de Lacan para complejizar y fortalecer el análisis discursivo de identidades, fenómenos y procesos políticos y sociales; y (2) Ofrecer algunas estrategias analíticas útiles para fortalecer la investigación empírico-discursiva de la operación hegemónica: ¿Qué contribuciones ofrece la figura lacaniana del nudo borromeo para complejizar y fortalecer el estudio de la construcción y reformulación discursiva de las identidades y fenómenos políticos y sociales? ¿Qué aportes específicos contiene esta herramienta clave de la teoría lacaniana para investigar la dinámica de estructuración y ruptura de las formaciones ideológicas? Finalmente, ¿qué implicancias epistemológicas y axiológicas pueden derivarse del uso del nudo borromeo para la investigación social crítica, desde una perspectiva posmarxista?

\section{Breves consideraciones teóricas sobre las herramientas lacanianas y sus usos en la investigación social}

Jacques Lacan (1901-1981) subvirtió y redefinió a la teoría psicoanalítica inaugurada por Sigmund Freud (1856-1939), a través de un innovador uso de conceptos de la lingüística estructuralista, la fenomenología y la teoría de los conjuntos ${ }^{3}$. Aunque Lacan predicó un "retorno a Freud" y se asumió como freudiano, lo hizo de una manera "herética" . En el marco de esta reformulación analítica, Lacan realizó fuertes críticas a Freud y al freudismo, sobre todo en la última etapa de su enseñanza'. En noviembre de 1963, en el momento en que comenzaba a dictar el Seminario sobre los "Nombres del Padre" y criticaba el "mito" del padre como un "Tótem" religioso de la teoría freudiana", la International Psychoanalytical Association (IPA) le prohibió que dictara aquel seminario. Acto seguido, Lacan fue expulsado de la IPA y el Comité de dicha organización proscribió y buscó anular su enseñanza ${ }^{7}$.

Como señala Alfredo Eidelsztein, entre 1965 y 1970 Lacan realizó un "giro de 180 grados", que criticó su anterior adhesión a la lingüística estructuralista y situó a su enseñanza "detrás del análisis del discurso". En el Seminario 17 Lacan caracterizó como una "payasada darwiniana" que "no tiene ni pies ni cabeza"9 la teoría del asesinato del padre de la horda primitiva de Freud, caracterizó como "inservible" al complejo de Edipo ${ }^{10}$ y construyó una novedosa teoría de los discursos sociales ${ }^{11}$. En el Seminario 18, Lacan profundizó la crítica al "padre mítico" de "Tótem y tabú"12. En este Seminario, además, Lacan volvió a referirse al "Nombre del Padre" y lo vinculó al falo como un significante "capaz de dar sentido al deseo de la madre"13. En el Seminario 19 y el Seminario 20 Lacan ahondó la crítica a la noción de "masa" de Freud y al "mito del Padre" que goza de "todas" las mujeres ${ }^{14}$. En el Seminario 22 Lacan llegó a sostener que "Freud no era lacaniano" tenido una "sospecha de lo simbólico, lo imaginario y lo real". Además, en R.S.I. Lacan vinculó a su tesis de la pluralidad de los nombres del padre con el nudo borromeo ${ }^{16}$. En contraste con la teoría lacaniana del nudo borromeo, Freud "no habría prescindido del nombre del padre"17. En esta etapa, a su vez, Lacan profundizó en

Yannis Stavrakakis, Lacan y lo politico, Prometeo-UNLP, Buenos Aires, 2007; Yannis Stavrakakis, La izquierda lacaniana, Fondo de Cultura Económica, Buenos Aires, 2010.

4 Manuel Murillo, "Versiones del nudo y los anudamientos a partir de lo real, lo simbólico y lo imaginario en Lacan", IV Congreso Internacional de Investigación y Práctica profesional en psicología, Facultad de Psicología, Universidad de Buenos Aires, Buenos Aires, p. 546.

Alfredo Eidelsztein, "Por un psicoanálisis no extraterritorial": El rey está desnudo, vol. 1 (2008), pp. 62 y ss.; Fabián Schejtman y Claudio Godoy, "Dos fases en el uso del nudo borromeo en el último período de la obra de Jacques Lacan": Anuario de Investigaciones, vol. 17 (2010), pp. 133-139; Manuel Murillo, "La hipótesis de los tres registros -Simbólico, Imaginario, Real- en la enseñanza de Jacques Lacan”: Anuario de Investigaciones, vol. 18 (2011), pp. 124 y ss.

6 Verónica Caamaño y Silvina Cochia, “Lo que se pluraliza del padre. No sin razón...”, IV Congreso Internacional de Investigación y XIX Práctica Profesional en Psicología, Facultad de Psicología, Universidad de Buenos Aires, Buenos Aires, 2012, p. 121.

Lacan sostuvo que el psicoanálisis debía ser entendido como "una acción concertada por el hombre, sea cual fuere, que le da la posibilidad de tratar lo Real mediante lo Simbólico". Es decir, la cura por la palabra. Como señala Constanza Ramírez Molano, "La formación del analista y la excomunión de Lacan": Nueva Escuela Lacaniana, vol. 14 (2006), decir esto tuvo un precio muy alto, por lo que el Comité Ejecutivo de la IPA decidió proscribir la enseñanza de Lacan. Además, puso como condición a los analistas que, para ser miembros de la IPA, en lo que tenía que ver con la formación del analista, la enseñanza de Lacan debía ser anulada.

Eidelsztein, "Por un psicoanálisis no extraterritorial", p. 75.

Jacques Lacan, Seminario 17. El Reverso del Psicoanálisis, Paidós, Buenos Aires, 2006, pp. 119-120.

Ibid., p. 104

1 Daniel Gutiérrez Vera, "La textura de lo social": Revista Mexicana de Sociología, vol. 66 (2004), pp. 311-343; Alicia Álvarez, La teoría de los discursos en Jacques Lacan, Letra viva, Buenos Aires, 2006.

Jacques Lacan, Seminario 18. De un discurso que no fuera del semblante, Paidós, Buenos Aires, 2009, pp. 132 y ss.

Ibid., p. 159.

Jacques Lacan, Seminario 19. “...ou pire” (1971-1972), versión íntegra (en español), Buenos Aires, s.f., pp. 11, 91; Jacques Lacan, Seminario 20. Aun. Paidós, Buenos Aires, 2008.

Schejtman y Godoy, "Dos fases en el uso del nudo borromeo en el último período de la obra de Jacques Lacan”, p. 137.

Caamaño y Cochia, "Lo que se pluraliza del padre. No sin razón...", p. 122.

Schejtman y Godoy, "Dos fases en el uso del nudo borromeo en el último período de la obra de Jacques Lacan”, p. 138. 
el uso de la teoría de los conjuntos y en conceptos originales, como la jouissance (goce) y el objeto pequeño a (petit a), construyendo una escuela propia (la Escuela de Orientación Lacaniana o EOL), con fuerte impacto y difusión en Europa y América Latina (en particular, en la Argentina, Brasil, México y Colombia).

En las últimas décadas, algunos de los principales referentes mundiales de la teoría política contemporánea y los estudios políticos posfundacionales utilizaron herramientas de la teoría lacaniana para el análisis sociopolítico $^{18}$. Yannis Stavrakakis, exponente de la teoría del discurso de Essex, sistematizó desde la "izquierda lacaniana" contribuciones de Ernesto Laclau (1935-2014) y Slavoj Žižek para el análisis de las hegemonías y las formaciones ideológicas ${ }^{19}$.

En Iberoamérica contamos también con una multiplicidad de investigaciones que emplearon herramientas lacanianas para el análisis de la operación hegemónica. Sin embargo, son escasos los estudios enfocados en las figuras geométricas no euclidianas que emplea Lacan. Nos referimos al nudo borromeo, la banda de moebius, el toro y la botella de Klein, entre otras figuras complejas que usa Lacan a partir de la teoría de los conjuntos y los matemas ${ }^{20}$. Si bien diferentes trabajos destacaron la importancia de estas herramientas para la teoría política y el análisis del discurso ${ }^{21}$, no desarrollaron estrategias metodológicas para la investigación social, en clave de la Teoría del Discurso.

En este trabajo colocaremos el eje en una de las herramientas más fascinantes de la teoría lacaniana: la figura del nudo borromeo, que ata entre sí al registro de lo Real con lo Simbólico y lo Imaginario (R.S.I.). Indagaremos en algunos de sus usos para complejizar el análisis de las identidades políticas. De este modo, pretendemos contribuir a fortalecer el desarrollo teórico-metodológico del análisis político del discurso para la investigación social. Para construir el artefacto analítico, nos centraremos en aportes de la última etapa de la enseñanza de Lacan (a partir del Seminario 19), ya que en esta etapa el psicoanalista francés profundizó en diferentes usos del nudo borromeo. Además, incluiremos conceptos convergentes de la teoría de la hegemonía de Laclau y la teoría de la ideología de Žižek, que son sistematizados por las contribuciones de Stavrakakis, así como de otros referentes del campo lacaniano. Exploraremos diferentes anudamientos entre los registros lacanianos, junto con su puesta en juego a nivel óntico-fenoménico. Ilustraremos con algunos ejemplos de estudios previos que emplearon esta herramienta para analizar identidades, fenómenos y procesos políticos y sociales en nuestra región.

\subsection{EI nudo borromeo en la teoría de Jacques Lacan}

Como señala el psicoanalista Manuel Murillo, Lacan retornó a Freud "orientado por tres registros que no son freudianos, sino lacanianos: lo Real, lo Simbólico y lo Imaginario"22 (R.S.I.). Estos elementos son introducidos como registros esenciales de la realidad humana en una temprana conferencia que Lacan dicta en 1953 en Saint Anne (Francia). En este texto, Lacan ${ }^{23}$ postuló por primera vez la existencia de tres registros propios de su enseñanza, a los que definió como lo Real, lo Simbólico y lo Imaginario ${ }^{24}$. Como indica Murillo: "Estos registros, que como tales no existen en la obra freudiana, constituyen una presencia constante en todos los seminarios y escritos de Lacan" ${ }^{25}$. De allí la relevancia crucial en su obra.

18 Slavoj Žižek, El sublime objeto de la ideología, Siglo XXI, Buenos Aires, 1992; Ernesto Laclau, Nuevas reflexiones sobre la revolución de nuestro tiempo, Nueva Visión, Buenos Aires, 1993; Ernesto Laclau, "Estructura, historia y lo político", en Judith Butler, Ernesto Laclau y Slavoj Žižek (comps.), Contingencia, hegemonía, universalidad. Diálogos contemporáneos en la izquierda, Fondo de Cultura Económica, México, 2003; Ernesto Laclau, La razón populista, Fondo de Cultura Económica, Buenos Aires, 2005; Ernesto Laclau, Los fundamentos retóricos de la sociedad, Fondo de Cultura Económica, Buenos Aires, 2014; Ernesto Laclau y Chantal Mouffe, Hegemonía y estrategia socialista, Fondo de Cultura Económica, Buenos Aires, 2004; Alain Badiou, Teoría del sujeto, Prometeo, Buenos Aires, 2009.

19 Stavrakakis, Lacan y lo politico; Stavrakakis, La izquierda lacaniana; Jason Glynos y Yannis Stavrakakis, "Lacan and Political Subjectivity: Fantasy and Enjoyment in Psychoanalysis and Political Theory": Subjectivity, vol. 24 (2008), pp. 256-274.

20 Mariana Gómez, "Cuerpo, goce y letra en la última enseñanza de Lacan”: Aesthethika, vol. 2 (2005), pp. 7-24. Schejtman y Godoy, "Dos fases en el uso del nudo borromeo en el último período de la obra de Jacques Lacan"; Eidelsztein, "Por un psicoanálisis no extraterritorial"; Murillo, "La hipótesis de los tres registros -Simbólico, Imaginario, Real- en la enseñanza de Jacques Lacan”; Murillo, "Versiones del nudo y los anudamientos a partir de lo real, lo simbólico y lo imaginario en Lacan".

21 Roque Farrán, "El concepto pensado como nudo borromeo": Žižek Studyies, vol. 3 (2009), pp. 1-23; Roque Farrán, "Badiou y Lacan: algunas consideraciones en torno a lo Real, la ontología y el concepto de sujeto en la práctica filosófica y psicoanalítica": El laberinto de arena, vol. 1, n. ${ }^{\circ}$ 1 (2013); Roque Farrán, "El anudamiento complejo de lo político: un análisis de la coyuntura argentina": Identidades, vol. 4, (2013), pp. 22-32; Daniel Gutiérrez Vera, "Ernesto Laclau: el populismo y sus avatares": Íconos, vol. 40 (2011), pp. 151-168; Hernán Fair, “Contribuciones del psicoanálisis lacaniano a la teoría política y social contemporánea y al análisis sociopolítico crítico": Revista de Ciencias Sociales, vol. 139 (2013), pp. 27-51; Hernán Fair, “Análisis Político del Discurso de Ernesto Laclau: una propuesta para la investigación social transdisciplinaria”: Íconos, vol. 54 (2016); Ian Parker y David Pavón-Cuéllar, Lacan, discurso, acontecimiento, Plaza y Valdés, Madrid, 2013; Ana Belén Blanco y María Soledad Sánchez, "Hacia una teoría social lacaniana": Miríada, vol. 13 (2017), pp. 171-191.

22 Murillo, "Versiones del nudo y los anudamientos a partir de lo real, lo simbólico y lo imaginario en Lacan", p. 545.

23 Jacques Lacan, "Lo simbólico, lo imaginario y lo real", Conferencia en París, Anfiteatro del Hospital psiquiátrico de Saint Anne, 8 de julio de 1953 , Escuela Freudiana de Buenos Aires (EFBA), versión crítica, Buenos Aires, 1953.

24 Stavrakakis, Lacan y lo politico, pp. 20-21; Murillo, "La hipótesis de los tres registros -Simbólico, Imaginario, Real- en la enseñanza de Jacques Lacan", p. 124.

25 Murillo, "Versiones del nudo y los anudamientos a partir de lo real, lo simbólico y lo imaginario en Lacan", p. 545. 
De acuerdo a Murillo, los registros R.S.I. condensan la teoría, la experiencia y la investigación psicoanalítica de Lacan, constituyendo la "marca" propia de su enseñanza:

RSI es la verdad a partir de la cual se estructura la experiencia analítica, la investigación y la formalización, es decir, el discurso de Lacan, el nombre propio o la marca singular de la enseñanza de Lacan ${ }^{26}$.

Pero, ¿a qué hace referencia Lacan con lo Real, lo Simbólico y lo Imaginario (R.S.I.)? Sucintamente, para Lacan: "Hay tres dimensiones del espacio habitado por el hablante, y esas tres dimensiones, tal como las escribo, se llaman lo Simbólico, lo Imaginario y lo Real" "27. En primer lugar, desde la teoría lacaniana, lo que definimos como la realidad social constituye una entidad que se construye y está determinada por el orden simbólico. En Lacan, lo Simbólico es lo que estructura el efecto de sentido (siempre equívoco) de lo que llamamos realidad. La dimensión de lo Imaginario, aunque implica una construcción del lenguaje, ya que "no es vehiculizado sino por lo que constituye lo simbólico", remite al modo ilusorio de constitución de la realidad social. Lacan lo asocia al plano de las "representaciones", vinculado a las identificaciones y las fantasías de los sujetos ${ }^{28}$. Este registro comienza con el Estadío del espejo, que genera las identificaciones imaginarias del sujeto. Sin embargo, como el orden significante estructura lo social, Lacan indica que: "La identificación imaginaria se opera por una marca simbólica" ${ }^{29}$. Lo Real, en cambio, representa un postulado de lo que, de lo simbólico, es estructuralmente "imposible" 30 , esto es, de aquello que es "estrictamente impensable" de las construcciones imaginarias. Pero la dimensión de lo Real (como concepto opuesto a la realidad) es también aquello que se muestra fenoménicamente mediante el orden simbólico y permite desestructurar las fantasías imaginarias y develar, retroactivamente, el carácter no-todo de la realidad simbólico-social. De allí que exista un anudamiento recíproco entre los tres registros (R.S.I.), sin que cada uno de ellos pierda su relativa autonomía y especificidad analítica.

A partir del Seminario 19 Lacan profundizó en diferentes modos de articulación compleja entre R.S.I. Para ello, hizo uso de una figura geométrica no euclidiana conocida como el nudo borromeo. En la clase del 9 de febrero de 1972 Lacan menciona por primera vez a la figura del nudo borromeo para mostrar cómo los registros de lo Real, lo Simbólico y lo Imaginario "se mantienen juntos" ${ }^{2}$. El nudo borromeo refiere, básicamente, a una estructura topológica triádica que anuda al menos tres elementos entre sí. En palabras de Lacan: "El nudo borromeo consiste estrictamente en que tres es su mínimo" ${ }^{33}$. Los tres registros están anudados a partir del lenguaje, que muestra las "relaciones recíprocas" que los encadenan ${ }^{34}$.

La principal característica del nudo borromeo es que estructura una relación de "mutua implicación" que enlaza a R.S.I. en una forma ternaria:

El nudo borromeo es una estructura topológica muy simple, cuya única propiedad resulta de la mutua implicación (enlace) de sus términos en número no menor de tres ${ }^{35}$.

A diferencia de otro tipo de estructuras topológicas, en el nudo borromeo basta que uno de los anillos se corte para que el conjunto se desintegre. En palabras de Lacan:

El nudo goza de la propiedad borromea: de seccionar yo uno cualquiera de los redondeles así combinados, todos los demás quedarán libres de golpe ${ }^{36}$.

La definición del nudo borromeo parte de tres, a saber, que si de tres ustedes rompen uno de los anillos, todos los otros están libres, es decir que los otros dos anillos son liberados ${ }^{37}$.

\footnotetext{
Ibid., p. 547.

Jacques Lacan, Seminario 21. Los incautos no yerran (Los nombres del padre) (1973-1974), versión íntegra (en español), Buenos Aires, s.f., p. 3.

Jacques Lacan, Seminario 9. La identificación (1961-1962), versión íntegra (en español), Buenos Aires, s.f.; Jacques Lacan, Seminario 22. R.S.I.

(1975-1976), versión íntegra (en español), Buenos Aires, s.f.

Lacan, Seminario 19. “...ou pire”, p. 91.

Ibid., p. 29; Lacan, Seminario 17. El Reverso del Psicoanálisis, p. 131.

Lacan, Seminario 22. R.S.I., p. 4.

Lacan, Seminario 19. “...ou pire”, p. 58.

Lacan, Seminario 22. R.S.I., p. 9.

Gutiérrez Vera "La textura de lo social", p. 323; Gómez, "Cuerpo, goce y letra en la última enseñanza de Lacan”, pp. 16-20; Stavrakakis, Lacan y lo político, p. 75; Schejtman y Godoy, "Dos fases en el uso del nudo borromeo en el último período de la obra de Jacques Lacan; Murillo, "La hipótesis de los tres registros -Simbólico, Imaginario, Real- en la enseñanza de Jacques Lacan"; Farrán, "Badiou y Lacan: algunas consideraciones en torno a lo Real, la ontología y el concepto de sujeto en la práctica filosófica y psicoanalítica", p. 2; Lacan, Seminario 20. Aun, pp. 20 y ss.

Farrán, "El concepto pensado como nudo borromeo", p. 2.

Lacan, Seminario 20. Aun, p. 157.

Lacan, Seminario 22. R.S.I., p. 9. Véase también Lacan, Seminario 19. “...ou pire”, p. 58; Seminario 21. Los incautos no yerran (Los nombres del padre), p. 12, Seminario 20. Aun, p. 149 y Seminario 23. El Sinthome, Paidós, Buenos Aires, 2012, pp. 20 y 30.
} 
En el marco de los anudamientos que entrecruzan y "suturan"38 a los tres registros, en el Seminario 19 Lacan introdujo la idea del nudo borromeo como "anillos borromeos", es decir, como una "cadena en la cual los eslabones se enlazan sin interpenetrarse, sin utilizar sus agujeros para el engarce" 39 . La cadena significante, que aparece en seminarios previos ${ }^{40}$, ahora es utilizada para ilustrar cómo el orden significante ata a los tres registros entre sí. Según Lacan: "Es necesario recordar que, cuando hablé de cadena significante, estaba siempre implicada esta concatenación"41. En el Seminario 20 Lacan utiliza la metáfora del "redondel de cuerda" para indicar que cada eslabón de R.S.I. "se dobla"42. En el Seminario 21, en cambio, usa la metáfora de "redondeles de hilo" ${ }^{43}$ que forman entre sí un "calce", de manera tal que:

Tomando las cosas por el calce, dicho de otro modo, por el nudo borromiano: un redondel de hilo es lo Real, un redondel de hilo es lo Simbólico, un redondel de hilo es lo Imaginario ${ }^{44}$.

En el mismo Seminario, $\operatorname{Lacan}^{45}$ apela también a la metáfora de la "trenza" para mostrar los anudamientos entre los redondeles de hilo. En el Seminario 22, cuyo nombre es R.S.I., Lacan afirma que el nudo es "una especie de cadena borromea" y que no tiene una forma cerrada, sino "abierta"46. En el Seminario 23 Lacan reafirma que, en realidad: "El nudo borromeo no es un nudo, es una cadena" ${ }^{47}$, por lo que "adquiere la forma sensible de una cadena borromea" 48 . Y luego sostiene que: "Me vi tentado a articular esta cadena, incluso a describirla, conjugando lo simbólico, lo imaginario y lo real" ${ }^{\prime 9}$. Se trata de una cadena borromea que, a través del orden significante, ata entre sí a los tres registros de su enseñanza. Pero a continuación Lacan realiza un nuevo y crucial aporte, al indicar que, en lo que refiere a la cadena R.S.I.: "Es importante considerarla como completamente flexible" 50 .

La cadena completamente flexible R.S.I. — en lugar de pensarlo como una cadena rígida — permite abordar diferentes modos de (des)anudamiento que se desplazan espacial y temporalmente. De manera tal que la articulación fenoménico-discursiva entre los tres registros: "Puede ser desanudada y articulada de otro modo, modificando y recombinando los términos en juego" 51 .

Esta conceptualización del nudo borromeo resulta central para analizar diferentes vínculos flexibles que (des)atan a los elementos del sistema. Como señala Roque Farrán, el nudo flexible permite abordar los entrecruzamientos recíprocos y fluidos que unen solidariamente a los tres registros. De este modo, Lacan:

Nos brinda además otra forma de entender la inter-posición (el término medio, el entre-dos) de manera alternada y no rígida: entre simbólico y real pasa (o cruza) lo imaginario, entre real e imaginario lo simbólico y entre imaginario y simbólico lo real. Apreciamos así que la consistencia no depende de uno en particular, que haga de conector o mediador, sino que cada uno cumple esta función en relación a los otros dos. A su vez, cada uno se ve interrumpido por otro en su cierre circular tautológico. Podemos decir que los términos son mutuamente "solidarios" $"$ 2.

El trípode R.S.I. como una cadena flexible y entrelazada acompañaría a Lacan hasta sus últimos escritos, en $1981^{53}$. Sin embargo, la estructuración del nudo borromeo tuvo diferentes etapas en la enseñanza de Lacan. Aunque R.S.I. estuvieron presentes desde su conferencia de 1953, es recién en su última etapa que el psicoanalista francés profundiza en los usos de estos tres registros anudados ${ }^{54}$.

Como señala Murillo, en esta última fase de su enseñanza, Lacan comprende a la realidad del sujeto como "un tejido de simbólico, imaginario y real" ${ }^{55}$. En esta estructura ternaria ya no hay una primacía de lo simbólico

\footnotetext{
Lacan, Seminario 23. El Sinthome, p. 70.

Schejtman y Godoy, "Dos fases en el uso del nudo borromeo en el último período de la obra de Jacques Lacan”, p. 134.

Véase, por ejemplo, Lacan, Seminario 9. La identificación; Seminario 17. El Reverso del Psicoanálisis.

Lacan, Seminario 19. “...ou pire”, p. 58.

Lacan, Seminario 20. Aun, p. 150.

Lacan, Seminario 21. Los incautos no yerran (Los nombres del padre), p. 3.

Ibid., p. 4. Énfasis añadido.

Ibidem.

Lacan, Seminario 22. R.S.I., p. 19.

Lacan, Seminario 23. El Sinthome, p. 85.

Ibid., p. 51.

Ibid., p. 104. Énfasis añadido.

Ibidem.

Farrán, "El concepto pensado como nudo borromeo", p. 3.

Ibid., p. 2.

Algunos autores afirman que, en la última etapa de la obra de Lacan, el uso del nudo borromeo tuvo dos fases. La primera transcurriría entre comienzos de 1972 y finales de 1973, y sería utilizado para el abordaje metafórico de la psicosis como corte del nudo. La segunda, entre finales de 1973 y 1975, el nudo se emplearía para analizar la neurosis. Véase Schejtman y Godoy, "Dos fases en el uso del nudo borromeo en el último período de la obra de Jacques Lacan".

54 Schejtman y Godoy, "Dos fases en el uso del nudo borromeo en el último período de la obra de Jacques Lacan; Murillo, "La hipótesis de los tres registros -Simbólico, Imaginario, Real- en la enseñanza de Jacques Lacan”.

55 Murillo, "La hipótesis de los tres registros -Simbólico, Imaginario, Real- en la enseñanza de Jacques Lacan”, p. 130.
} 
(como en su texto inaugural de 1953), sino que los tres registros son igualmente importantes y funcionan en un mismo nivel analítico. Como sostiene Farrán: “Aquí no hay estructura jerárquica, no hay uno más importante que el resto, cada uno de los términos es necesario para sostener al conjunto" 56 . De hecho, para Lacan el nudo R.S.I. también puede ser ordenado con otras variantes, como I.R.S., R.I.S. o S.I.R. ${ }^{57}$. En este sentido, "el concepto-nudo pretende restituir la equivalencia estricta entre los términos, sus registros y las operaciones de enlace" ${ }^{\prime 5}$. En palabras de Lacan:

Ninguno de los redondeles es de un tipo diferente de los demás. No hay ningún punto privilegiado, y la cadena es estrictamente homogénea ${ }^{59}$.

Esto parte de otra manera de considerar el espacio; y al calificar a esas tres dimensiones enhebrándolas a los términos que incluso pareció que yo, precisamente, diferencié los términos Simbólico, Imaginario y Real, lo que estoy anticipando es que se los ha hecho estrictamente equivalentes ${ }^{60}$.

Lo importante es que, aunque estén pintados de colores diversos uno con relación al otro, esos tres redondeles, esos redondeles de hilo son estrictamente equivalentes. Quiero decir que lo importante es que tanto lo Real como lo Imaginario como lo Simbólico pueden jugar exactamente la misma función con relación a los otros $d o s^{61}$.

A partir de este uso innovador del nudo borromeo, Lacan postuló la confluencia, el equilibrio y la superposición recíproca entre lo Real, lo Simbólico y lo Imaginario:

El pensamiento de lo Real se supone, justamente, por el hecho de existir. Pero, ¿qué resulta de ello sino que nos hace falta concebir estos tres términos confluyendo unos con otros?, ¿No puede suponerse que son tan análogos, para utilizar este término, debido a una continuidad? Esto es lo que nos conduce derechito a hacer $e l$ nudo de tres. En efecto, por la manera en que estos tres [registros] se equilibran, se superponen, no hay que hacer muchos esfuerzos para reunir los puntos de aplanamiento que les darán continuidad ${ }^{62}$.

Otro aspecto relevante para comprender la dinámica del nudo borromeo es la dimensión temporal. A partir del corte de lo Real y la posterior sutura simbólico-imaginaria, Lacan encadena el análisis sincrónico con la dimensión de temporalidad. En este sentido, Farrán destaca las intersecciones diacrónicas entre el nudo borromeo y los "puntos nodales triples que organizan las estructuraciones" entre los registros. Es decir:

Los sitios donde se produce el calce entre los tres cordeles del nudo borromeo, y, en términos discursivos, donde Real, Simbólico e Imaginario convergen a un tiempo, entrelazándose alternativamente uno sobre otro ${ }^{63}$.

Desde esta lógica: "La nodalidad se verifica por el corte, lo que introduce la dimensión temporal en esta representación espacial: corte, desanudamiento y nueva sutura" ${ }^{\prime 4}$. De manera tal que, en el entrelazamiento entre Real, Simbólico e Imaginario, la dimensión del tiempo rompe con la lógica sincrónica del espacio social. En palabras de Lacan, el anudamiento borromiano de las dimensiones de R.S.I. permite mostrar cómo "el espacio implica al tiempo" ${ }^{65}$.

Por lo tanto, el anudamiento borromeico no es un fenómeno meramente sincrónico, sino que funciona, a su vez, a través de una dinámica de transformación temporal (histórica). Como señala Farrán, el nudo borromeo es producto del "devenir de un proceso de articulación compleja que es, simultáneamente, histórico y estructural" 66 . El mismo Lacan reconoce que existen "breves emergencias históricas" que permiten alcanzar un "fragmento de lo Real"67. Para Alain Badiou, incluso, con la "primacía del nudo" de esta etapa de la enseñanza de Lacan: "Es la vertiente histórica la que se impone sobre la estructural"68.

Recordemos que, en la lectura del nudo borromeano de Lacan, lo Real se entrelaza al registro de lo Simbólico, de manera tal que el acceso a lo Real sólo es posible a través del orden significante:

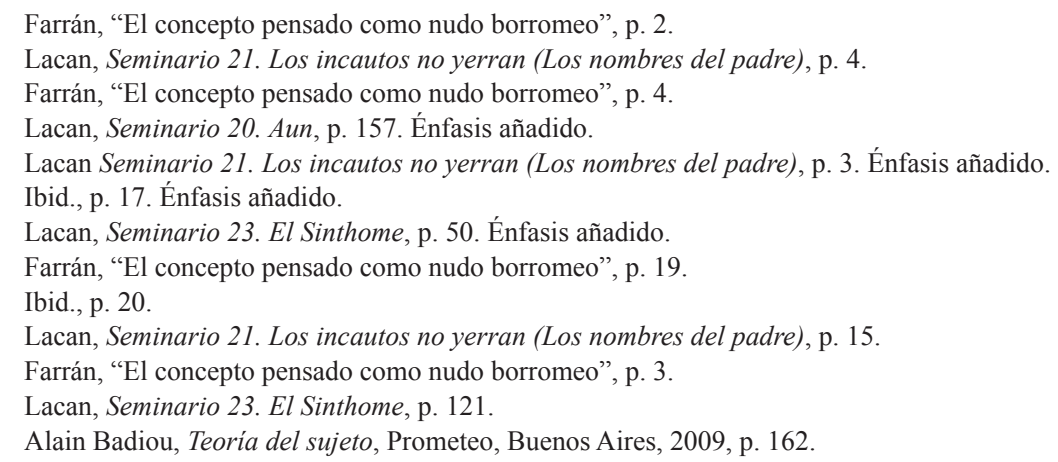


Ese Real del cual yo hablo y cuyo discurso analítico está hecho para recordarnos que su acceso es lo Simbólico, dicho Real es, en y por ese imposible, que sólo define lo simbólico que accedemos a él ${ }^{69}$.

Uno de los modos en los que se manifiesta a nivel fenoménico-temporal (óntico) lo Real es a partir de su simbolización en el síntoma. En el Seminario 22 Lacan define al síntoma como un efecto de la entrada de lo simbólico en lo Real:

Si lo Real se manifiesta en el análisis, y no solamente en el análisis, si la noción de síntoma ha sido introducida mucho antes que Freud por Marx, de manera de hacer de él el signo de algo que es lo que no anda en lo Real, si, en otros términos, somos capaces de operar sobre el síntoma, esto es en tanto que el síntoma es del efecto de lo simbólico en lo Real ${ }^{70}$.

De este modo, si bien lo Real (que no debe confundirse con la realidad) no puede ser atrapado, Lacan señala que, al estar anudado al orden significante, en el síntoma un fragmento de lo Real puede ser tocado, se manifiesta ónticamente y es simbolizado a través de las construcciones del lenguaje ${ }^{71}$.

Recordemos que, en la teoría lacaniana, el inconsciente se estructura como un lenguaje coherente, a partir de metáforas y metonimias que remiten a formas simbólicas de condensación y desplazamiento ${ }^{72}$. Así, a través de sus modos de sintomatización simbólica, lo Real se manifiesta en la realidad fenoménica. Dicha presentificación fenoménico-significante desestabiliza la realidad simbólica del sujeto y exhibe, en sus efectos sintomáticos, el carácter imaginario (fracturado, fallido, no todo) de lo social ${ }^{73}$. Como indica Daniel Gutiérrez Vera:

El psicoanálisis considera que toda configuración simbólica —y la política entre otras — se ve constantemente alterada por la dimensión del Real que se muestra en el síntoma manifiesto a escala del sujeto particular o del grupo, que como factor de inercia afecta el espacio tropológico del discurso hasta desestabilizarlo ${ }^{74}$.

En la clase del 11 de marzo de 1975 del Seminario 22, Lacan incluye un aspecto adicional al nudo que define como "nominación". Lacan vincula la nominación al "Nombre del padre" en su "función radical que es dar un nombre a las cosas, con todas las consecuencias que eso comporta" ". Como señala Murillo, el Nombre del padre cumple la función de anudar a los registros mediante un redoblamiento de alguno de ellos:

Dado que los nombres del padre para Lacan son lo Real, lo Simbólico y lo Imaginario, la nominación que anuda a RSI no es sino un redoblamiento de alguno de estos tres registros ${ }^{76}$.

Sin embargo, Lacan aclara que la nominación no implica un cuarto registro ya que, como el orden significante estructura lo social, lo que da nombre-consistencia también "forma parte de ese Simbólico"77.

$\mathrm{Al}$ abordar los anudamientos discursivos que atan a lo Real, lo Simbólico y lo Imaginario, Lacan plantea a este modo de entrelazamiento como "una hipótesis original"78. Ello supone una contribución original de su enseñanza, en tanto diferente a la de Freud. De hecho, con la topología de nudo borromeo Lacan discutió con el mismo Freud. En la intervención pública del 12 de julio de 1980 en Caracas (Venezuela), Lacan dejó en claro - sin dejar de situarse como freudiano - los intensos debates y contrapuntos que mantuvo con Freud, y se refirió a "cierta torpeza" de su segunda tópica:

Sean ustedes lacanianos, si prefieren. Yo soy freudiano. Por eso creo adecuado decirles algunas palabras del debate que mantengo con Freud, y que no es de ayer. Aquí está: mis tres no son los suyos. Mis tres son lo Real, lo Simbólico y lo Imaginario. Me vi llevado a situarlos con una topología, la del nudo, llamado borromeo. El nudo borromeo pone en evidencia la función de al-menos-tres. Anuda a los otros dos desanudados. Eso les di yo a los míos. Se los di para que supieran orientarse en la práctica. ¿Pero se orientan mejor que con la tópica legada por Freud a los suyos? Hay que decirlo: lo que Freud dibujó con su tópica, llamada segunda, adolece de cierta torpeza. Me imagino que era para darse a entender dentro de los límites de su época ${ }^{79}$.

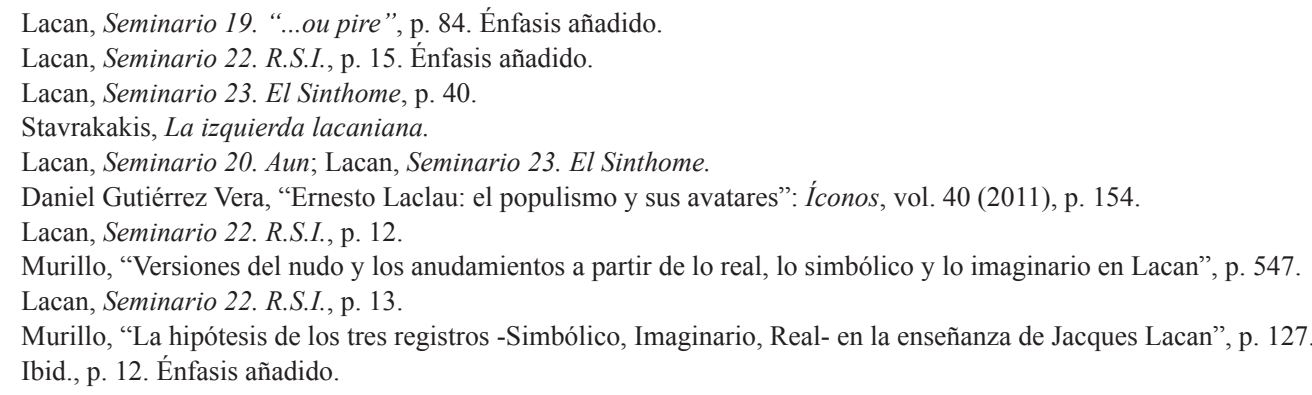


Ahora bien, en el Seminario 23 Lacan reformula el abordaje previo del nudo borromiano, a partir de la noción de "sinthome". En este Seminario Lacan "integra el sinthome a la problemática del nudo [borromeo], construido a partir de los tres registros: Real, Simbólico e Imaginario" 80 . De este modo, incluye un "cuarto" elemento que se enlaza a R.S.I. en el nudo ${ }^{81}$. Según Lacan, "plantear el lazo enigmático de lo simbólico, lo imaginario y lo Real implica o supone la existencia del síntoma" ${ }^{82}$. En este seminario, además, Lacan refiere al concepto de "sinthome borromeo" como "Algo que permite a lo simbólico, lo imaginario y lo Real mantenerse juntos" $"$. De esta manera, la noción de nudo borromeo trasciende la formalización abstracta y permite "leerlo" en sus diferentes "versiones": desde el Estadío del espejo, hasta la estructuración del sujeto y del sinthome ${ }^{84}$.

\section{Usos del nudo borromeo en la teoría del discurso y las identidades políticas}

A pesar de la indudable relevancia del nudo borromeo de Lacan (y los aportes complementarios desde la filosofía de Badiou), este concepto ha sido escasamente utilizado desde la Teoría Política del Discurso. Si bien el propio Laclau reconoció en su obra la "presencia de lo Real dentro de lo simbólico" 85 y destacó su capacidad de "acceso al nivel de la representación a través de contenidos ónticos" - del mismo modo que la inmensa mayoría de sus seguidores y discípulos - en los usos del nudo borromeo para el análisis político. Incluso los trabajos de Stavrakakis, principal exponente de la izquierda lacaniana, no ahondaron en la figura específica del nudo borromeo en la investigación social, y esta herramienta clave de la teoría lacaniana tampoco aparece replicada en el trabajo metodológico más sistemático de la perspectiva laclauiana ${ }^{87}$.

En este trabajo se sostiene que el uso de la figura del nudo borromeo contribuye a fortalecer los estudios sobre la hegemonía. Ello se debe a que permite mostrar, a través de su sobredeterminación discursiva, la dinámica de articulación y desplazamiento óntico-fenoménico (histórico) entre sus eslabones. Nuestra hipótesis principal afirma que, desde un APD, el nudo borromeo permite examinar diferentes modalidades de articulación del lazo social y de desanudamiento entre los elementos particulares. De esta manera, se contribuye a complejizar y fortalecer el análisis discursivo de identidades, fenómenos y procesos políticos y sociales. Como hipótesis auxiliar sostenemos, además, que el nudo borromeo tiene implicancias epistemológicas y axiológicas relevantes para la investigación social crítica.

\section{Tres modalidades de anudamiento borromeico de lo social}

La figura del nudo borromeo permite ilustrar diferentes modalidades complejas y flexibles de (des)articulación discursiva del lazo social. Recordemos que, para Lacan, el discurso "instaura un tipo de lazo social definido" 88 . En este trabajo proponemos distinguir tres modalidades de anudamiento borromeico entre lo Real, lo Simbólico y lo Imaginario para el APD: contingentes-de mutua imbricación, esencialistas-perversos y esencialistas-psicóticos. Cada uno de estos vínculos sociales (ya que no se trata de formas enfermizas o puramente individuales) representa diferentes formas discursivas de estructurar el lazo (como grupo, asociación u organización con un número mínimo de tres).

\subsection{Anudamientos contingentes y de mutua imbricación}

Entrelaza los elementos del conjunto, preservando la relativa y parcial autonomía de cada elemento particular. Se caracteriza por aceptar la alteridad y el carácter construido, histórico, precario, fallido y no-todo de lo social. Se estructura mediante una interdependencia recíproca entre sus eslabones, que acepta la castración simbólica como constitutiva. En este tipo de anudamientos los elementos particulares están articulados (de un modo

\footnotetext{
Gómez, "Cuerpo, goce y letra en la última enseñanza de Lacan”, p. 18.

Lacan, Seminario 23. El Sinthome, p. 20.

Ibidem.

Ibid., p. 92. El concepto de sinthome de Lacan es motivo de intensas controversias dentro del campo lacaniano (véase Roberto Mazzuca, Santiago Mazzuca, Marcelo Mazzuca y Carolina Zaffore, "Diferentes lecturas de la noción lacaniana de identificación con el síntoma": Anuario de Investigaciones, vol. 21 (2014), pp. 93-100). En este trabajo nos enfocaremos en la noción básica del nudo borromeo de Lacan, por lo que dejaremos de lado esta última relectura del sinthome.

84 Murillo, "Versiones del nudo y los anudamientos a partir de lo real, lo simbólico y lo imaginario en Lacan", p. 548.

Laclau, La razón populista, p. 152.

Laclau, "Estructura, historia y lo político", p. 187.

Jason Glynos y David Howarth, Logics of critical explanation in social and political theory, Routledge, Abingdon, Great Britain, 2007.

Lacan, Seminario 19. “...ou pire”, p. 29
} 
contingente) en términos equivalenciales ${ }^{89}$. Ello implica que A se encuentra en una relación de equivalencia $(\equiv)$ con $\mathrm{B}$ y con $\mathrm{C}$. Esto supone que $\mathrm{A}$ no es igual a $\mathrm{B}$ ni tampoco a $\mathrm{C}$, sino que $\mathrm{A}$ es diferente a $\mathrm{B}$ y a $\mathrm{C}$. Es decir: A\#B y A\#C y, al mismo tiempo, B\#C, de manera tal que A\#B\#C. También implica que el conjunto entrelazado siempre permanece (y debe permanecer) abierto a la alteridad y, por lo tanto, a la aceptación de la dislocación (como un nombre de lo Real) y el desplazamiento contingente y temporal de los elementos. Es decir, que en este tipo de lazo social tanto los sujetos, como el sistema que los enlaza, están atravesados por la falta, barrados (\$), agujereados como conjunto (Ø) y abiertos a la transformación histórica. Los anudamientos contingentes y de mutua imbricación son propios de lo que la Teoría del Discurso de Laclau define como la operación hegemónica.

\subsection{Anudamientos esencialistas-perversos}

Se caracterizan por constituir una relación fantasmática de unidad plena y esencial entre los elementos del conjunto, que intenta negar el carácter histórico, precario, fracturado, fallido y no-todo de lo social. Lo definimos como una estructura discursiva perversa, ya que desmiente la falta en el Otro, niega la castración simbólica y pretende desconocer los límites constitutivos de lo Real ${ }^{90}$. Ello para intentar alcanzar un ideal (imposible) de completitud, transparencia y armonía social. En la dinámica política, los anudamientos perversos se pueden manifestar a través de una lógica de acción de cinismo posmoderno ${ }^{91}$, que sigue la célebre fórmula de Mannoni: "Ya lo sé, pero aun así" ${ }^{\prime 2}$ o, en palabras de Lacan: "Seguramente no, pero aun así" ${ }^{\prime 93}$. En este tipo de relaciones sociales inconscientemente se hace de cuenta que $A=B=C$ y que el sistema es cerrado y homogéneo $(O)$, aunque en realidad se sabe que $\mathrm{A} \equiv \mathrm{B} \equiv \mathrm{C}$, y que la falta y la alteridad son constitutivas.

\subsection{Pseudo anudamientos esencialistas-psicóticos}

Se caracterizan por construir una relación fantasiosa de unidad homogénea, ahistórica y plena de lo social, que rechaza radicalmente las diferencias, las fallas de lo Real y los desplazamientos históricos entre los elementos del sistema. En este tipo de relaciones imaginarias todos los elementos del conjunto forman una igualdad esencial, pura y atemporal, como si constituyeran un cuerpo homogéneo, uniforme y eterno, que pretende alcanzar la mítica unidad con la Cosa. Esto es, un Uno-todo como masa uniforme e inalterable que niega la falta constitutiva y rechaza las diferencias particulares. Así: $A=B=C$, y entre estos registros se forma una unicidad cerrada, esencial e inalterable (0). Son articulaciones fantasmáticas, ya que estructuran una fantasía esencialista de uniformidad que rechaza la castración simbólica y el carácter contingente, histórico, precario, fallido y no-todo de lo social. A diferencia de las estructuras perversas, las estructuras discursivas psicóticas no desmienten lo Real, sino que lo niegan radicalmente y, fenoménicamente, buscan triturar las particularidades, diferencias y singularidades que son inherentes a lo social ${ }^{94}$.

En sentido estricto, este tercer tipo de relación destruye fácticamente la lógica del nudo borromeo y aniquila de hecho todo lazo social, ya que rechaza lo Real y desconoce los aspectos simbólicos como constitutivos ${ }^{95}$. De este modo, asume la forma de lo que Laclau ${ }^{96}$ define como una ideología, en tanto deseo fantasioso de eliminar los antagonismos y la contingencia de lo social, para alcanzar una sociedad transparente, sin fisuras ni divisiones.

89 Laclau y Mouffe, Hegemonía y estrategia socialista.

90 Como señala Braunstein, en Lacan el término perversión no refiere a una patologización psicologista, sino que forma parte de una estructura discursiva en el que "[e]l deseo no afirma la falta, antes bien, la niega y la niega justo allí donde aparece la prohibición de gozar: en el Otro. El Otro no puede y no debe estar castrado" (Néstor Braunstein, El goce. Un concepto lacaniano, Siglo XXI, Buenos Aires, 2006, p. 255). La perversión, además, no se reduce a aspectos individuales ni meramente clínicos, sino que forma parte de una particular estructura discursiva de identificación que adquiere un sentido relacional y social (Lacan, Seminario 9. La identificación, p. 256). Sobre la lógica de la perversión en la teoría lacaniana, véase también Diana Rabinovich, El concepto de objeto en la teoría psicoanalítica, Manantial, Buenos Aires, 2003, pp. 142-143.

91 Žižek, El sublime objeto de la ideología.

2 Braunstein, El goce. Un concepto lacaniano, p. 250.

3 Lacan, Seminario 19. “...ou pire”, p. 40.

94 En el Seminario 20 Lacan se refiere a la "psicosis borromea” a partir del corte y sostiene que "la falta de un eslabón libera a todos los demás". De este modo, "el encadenamiento psicótico es planteado así, a esta altura de su enseñanza, como borromeo; y su desencadenamiento -y lo particular de algunos de los fenómenos que lo caracterizan- como la ruptura de esta cadena borromea de significantes por la liberación de Uno" (citado en Schejtman y Godoy, "Dos fases en el uso del nudo borromeo en el último período de la obra de Jacques Lacan”, p. 135). En el Seminario 23, por su parte, Lacan menciona a la psicosis paranoica como una estructura de la subjetividad en la que "[1]o imaginario, lo simbólico y lo Real son una sola y misma consistencia" (Lacan, El sinthome, p. 53). Siguiendo a Braunstein (El goce. Un concepto lacaniano, p. 247 y ss.), decimos que el discurso psicótico ni siquiera se pregunta sobre la castración fálica y las fallas de lo Real que impiden el acceso al goce pleno de la Cosa.

95 Como señala Lacan, en la estructura psicótica: "Lo Real y lo Simbólico, fantasma y realidad, no han podido jamás ser delimitados, a falta de haber podido acceder a esta tercera dimensión que es la única que permite esta diferenciación indispensable entre esos dos niveles: lo imaginario". Lacan, Seminario 9. La identificación, p. 257.

96 Laclau, Nuevas reflexiones sobre la revolución de nuestro tiempo; Laclau, Los fundamentos retóricos de la sociedad. 
Un ejemplo típico de estas fantasías ideológicas son los fundamentalismos políticos, como los segregacionismos étnico-raciales y religiosos, los fascismos y los totalitarismos. Estas ideologías esencialistas pretenden alcanzar una fantasía del Pueblo-Uno ${ }^{97}$ como una masa uniforme, homogénea y eterna, y buscan triturar fenoménicamente las diferencias sociales como aspectos constitutivos y deseables. Las construcciones tecnocráticas (como es el caso de la ideología neoliberal) comparten la misma lógica fantasmática, a partir de la creencia en una supuesta objetividad pura, no mediada por los aspectos simbólicos, ni atravesada por las fallas de lo Real. Más allá de sus diferencias de contenido y de grado de estructuración, estos fenómenos ideológicos convergen en su pretensión de eliminar el síntoma, la alteridad y la contingencia de lo social, para alcanzar una fantasía de uniformidad y transparencia, sin resto.

\section{Modos, tipos, tiempos e intensidades de entrelazamiento borromeico entre los elementos del sistema}

El concepto de cadena borromea flexible también permite analizar diferentes clases de anudamientos recíprocos entre los elementos particulares. Distinguimos entre los tipos de anudamientos, su extensión social, su intensidad/fuerza relativa y su tiempo de estructuración y sedimentación social.

\subsection{Tipos de anudamientos}

En primer lugar, diferenciamos analíticamente entre tipos de anudamientos borromeicos simples y complejos:

1. Anudamientos simples: entre A, B y C sólo existe un único tipo de lazo social. Por ejemplo: un lazo borromeo de una sola vuelta entre los sujetos, reducido a una lógica económico-instrumental (del tipo costo-beneficio). Esta lógica político-discursiva se vincula al juego de intereses económicos y al empleo de una racionalidad instrumental, propia del Discurso Capitalista ${ }^{98}$.

2. Anudamientos complejos: entre A, B y C existe, de forma simultánea, más de un lazo articulatorio. Por ejemplo: puede existir un doble nudo que enlaza a nivel económico-instrumental y afectivo-emocional. $\mathrm{O}$ un triple nudo económico, institucional y afectivo. La existencia de diferentes tipos de anudamientos refuerza el vínculo entre los elementos y acrecienta la probabilidad de persistencia del lazo entre las partes, en comparación con lazos borromeicos simples, que no disponen de anudamientos simultáneos en varios niveles diferentes.

\subsection{Extensión o longitud del anudamiento}

En segundo término, identificamos diferentes modalidades de anudamiento entre los elementos del conjunto, a través de su extensión o longitud. Aquí podemos distinguir entre nudos borromeicos de tres elementos, nudos de cuatro y nudos mayores a cuatro elementos del sistema.

\subsection{Intensidad o fuerza del anudamiento}

En tercer lugar, identificamos intensidades diferenciales de anudamiento fenoménico-discursivo entre los elementos particulares del sistema. Ello permite abordar comparativamente $-\mathrm{y}$ distinguir en términos de gradientes - la fuerza o intensidad relativa de imbricación del lazo social:

1. Anudamiento débil: supone un tipo de articulación discursiva del lazo social entre los elementos superfluo, frágil y débilmente estructurado.

2. Anudamiento fuerte: supone un tipo de articulación discursiva entre los elementos sólido, consistente y fuertemente estructurado.

Aquellos lazos sociales que se encuentran más fuertemente anudados tienen el potencial de estructurar de un modo más persistente la articulación borromeica, ya que su desatamiento se hace más dificultoso.

\subsection{Tiempo de sedimentación del anudamiento}

La cuarta variable a considerar para el APD es el tiempo de sedimentación del anudamiento borromeico. Las identidades que se encuentran relativamente más estructuradas en el tiempo, producto de su parcial sedimentación histórica, tienen más probabilidades de fortalecer exitosamente el lazo social y perdurar temporalmente. Entre los factores que contribuyen a sedimentar en el tiempo el lazo social encontramos:

97 Claude Lefort, La invención democrática, Nueva Visión, Buenos Aires, 1990.

98 Lacan, Seminario 17. El Reverso del Psicoanálisis. 
1. El factor afectivo, asentado en la vivencia de compartir determinadas relaciones de amistad fraterna y cercanía social.

2. El factor valorativo, asentado en la vivencia de compartir determinados valores e ideales en común.

3. El factor tradicional, asentado en la vivencia de compartir determinadas tradiciones históricas y costumbres ancestrales fuertemente arraigadas.

4. El factor institucional, garantizado por el marco jurídico-legal tipificado por escrito y la amenaza del uso monopólico de la coerción física legítima por parte del Estado.

5. El factor instrumental-económico, basado en la vivencia de compartir una asociación común guiada por una lógica racional-formal o instrumental, inscripta dentro de la lógica de funcionamiento del discurso capitalista.

$\mathrm{Al}$ desplazarse de la caracterización formal a la dinámica política concreta, el analista del discurso puede observar y atribuir la existencia de lógicas discursivas superpuestas que encadenan y mixturan, en diverso grado y con diferente intensidad o fuerza relativa, aspectos emocionales (afectivos, inconscientes) y racionales (tanto valorativos como instrumentales), propios de los condicionantes sociales y la subjetividad de los agentes.

A partir de un abordaje contextualizado de la dinámica sociopolítica, el analista del discurso puede examinar la consistencia relativa de los anudamientos borromeicos. Desde una perspectiva diacrónica, también puede analizar las transformaciones y reformulaciones históricas en las relaciones, que pueden debilitar y/o fortalecer relativamente la intensidad del lazo social, o incluso cortar determinadas relaciones parcialmente sedimentadas y objetivadas.

\section{El nudo como metáfora del entrelazamiento entre las dimensiones, planos y registros de lo social}

Usado como metáfora, el anudamiento borromeico también permite abordar diversos modos de entrelazamiento discursivo entre las dimensiones, planos, niveles y registros de la realidad. El propio Lacan sostiene, en el Seminario 21, que el nudo borromiano R.S.I. debe ser pensado como "cubos" que tienen diferentes "dimensiones". Según Lacan: "La idea es hacer algo que responda a tres planos" "99. En particular, se trata de experimentar que hay "tres dimensiones del espacio", es decir, lo Simbólico, lo Imaginario y lo Real ${ }^{100}$.

Desde una perspectiva posgramsciana, el nudo permite mostrar los anudamientos que atan a los planos de lo político, lo económico y lo social, sin eliminar la especificidad de cada elemento. Desde una concepción borromeica, estos planos no pueden considerarse como esferas cerradas, sino que están imbricados entre sí y se entrelazan a través del orden significante. Sin embargo, ello no implica que cada elemento pierda su relativa autonomía como ente propio y diferente del resto. En caso contrario, la relación de mutua imbricación se convertiría en una subsunción pura, que eliminaría el carácter diferencial de cada elemento y convertiría al sistema en una totalidad homogénea y sin fisuras. Así, la política está imbricada fenoménicamente con los intereses económicos de los sujetos, que a su vez se entrelazan en relaciones intersubjetivas, y estos elementos — abiertos a la alteridad - están sobredeterminados por el orden significante. Algo similar ocurre entre la política, la ciencia y la ética, en tanto que toda ciencia está imbricada subjetivamente de determinados valores éticos y políticos. Pero ninguno de estos elementos particulares puede ser absorbido o subsumido en su totalidad por los otros elementos sin que el encadenamiento se autodisuelva.

En la misma lógica se pueden explicar los cruces e intersecciones que existen entre las diferentes disciplinas sociales y humanísticas. Desde un APD, estos elementos se encuentran (y deben mantenerse) mutuamente imbricados, aunque no por ello pierden su relativa y parcial autonomía como entes propios. En caso contrario, se correría el peligro de eliminar las particularidades y especificidades relativas de cada disciplina.

Desde la Teoría Política del Discurso, el nudo borromiano flexible y la noción de entrelazamiento también puede utilizarse como metáfora para ilustrar los modos de articulación equivalencial ${ }^{101}$ entre los significantes y la función del punto nodal en la operación hegemónica. En este sentido, en una investigación previa analizamos la intensa articulación equivalencial que el discurso menemista logró establecer entre la Ley de Convertibilidad, las reformas estructurales del paradigma neoliberal y la estabilidad económica, que formaron retóricamente un núcleo nodal ${ }^{102}$. Este encadenamiento fantasioso entre los significantes, y su "efecto de nodalidad" 103 , puede ser asimilado a la lógica del nudo borromeo ideológico ya que, desde el discurso menemista, se constituyó (imaginariamente) como un conjunto cerrado, eterno e inalterable.

\footnotetext{
Lacan, Seminario 21. Los incautos no yerran (Los nombres del padre), p. 12.

Ibid., p. 15.

Laclau y Mouffe, Hegemonía y estrategia socialista.

102 Hernán Fair, "El (no) debate político e ideológico en torno al núcleo nodal de la hegemonía neoliberal en la Argentina": PostData, vol. 19 (2014), pp. 583-635.

103 Lacan, Seminario 21. Los incautos no yerran (Los nombres del padre), p. 26.
} 
Cabe destacar, por último, que, como en la teoría de Lacan las relaciones entre los registros no se limitan a los tres anillos circulares del nudo borromeo básico, pueden analizarse articulaciones borromeanas entre más de tres elementos.

\section{Usos del nudo borromeo para el análisis discursivo de identidades, fenómenos y procesos políticos y sociales}

La lógica del nudo borromeo no solo permite indagar en diferentes anudamientos discursivos entre los elementos del sistema. Además, permite abordar sus modos de reformulación y ruptura a nivel espaciotemporal. Según sostenemos, desde un APD, el nudo borromeico contribuye a analizar diferentes modos de enlazamiento entre Real, Simbólico e Imaginario que se desplazan, se reformulan y se destruyen fenoménicamente. Específicamente, permite analizar los modos de simbolizar, imaginariamente, lo Real en las fantasías ideológicas y su entrelazamiento con los acontecimientos disruptivos y los síntomas, en la dinámica histórico-política.

\subsection{EI nudo borromeo en el análisis de las fantasías ideológicas que simbolizan e intentan atrapar a lo Real}

En la teoría lacaniana las fantasías se caracterizan por construir, a través del orden simbólico, un imaginario que niega lo Real y trata de "suplir" la "relación sexual"104. En el Seminario 20 Lacan apela a la figura del nudo borromeo para vincular a las fantasías con los intentos del sujeto de simbolizar lo Real y llenar la falta en el Otro $^{105}$. Como señala el psicoanalista Daniel Gutiérrez Vera, en el centro de intersección de estos tres registros anudados hay un agujero que el sujeto intenta llenar a través de las fantasías:

La dimensión del imaginario, en tanto registro de las identificaciones, se ata en el nudo borromeo del Real, Simbólico e Imaginario para configurar lo que se reconoce como 'realidad' política y social. En el centro de intersección de estos tres registros se abre un insondable agujero, que el sujeto llena con todo tipo de fantasías ${ }^{106}$.

Para el análisis sociopolítico el estudio de las fantasías resulta crucial, ya que estas ofrecen la promesa (ilusoria) de "colmar la falta" de un modo definitivo, atrapar a lo Real y, de este modo, lograr un estado anhelado de completud ${ }^{107}$.

El nudo borromeo resulta particularmente útil para abordar las formaciones ideológicas, ya que permite analizar el funcionamiento de diferentes tipos de fantasías (objetivistas, corporativistas, evolucionistas, etc.) que, con diverso grado de estructuración, tratan de capturar a lo Real para alcanzar un ideal de armonía social.

\subsection{Los límites históricos de la fantasía ideológica: el nudo borromeo en el análisis de los síntomas que simbolizan lo Real en la dinámica política}

La lógica de entrelazamiento y corte del nudo borromeo a nivel espacio-temporal también contribuye a analizar los límites históricos (Reales) de las operaciones ideológicas y su sintomatización a través del orden simbólico. Recordemos que en Lacan lo Real expresa lo "imposible" y ello se manifiesta como un "retorno de lo reprimido" 108 a través del síntoma, que desbarata simbólicamente la estructuración imaginaria de lo social y muestra su carácter fantasmático. Como señala Fridman, en Lacan el síntoma es "el punto de entrelazamiento de lo Simbólico y lo Real". Y "es en su función de anudamiento que permite una cierta consistencia, con la cual el sujeto puede identificarse, vanagloriarse o padecer"109. Debido a que, para Lacan, "El lenguaje opera su captura de lo Real" 110 , y lo hace a través de síntomas que "están enganchados al lenguaje" verdad" que emerge para simbolizar la realidad reprimida puede estudiarse a través del análisis discursivo de los síntomas que se manifiestan en la dinámica sociopolítica.

Los síntomas que emergen de lo Real se expresan fenoménicamente cuando las ideologías muestran fisuras discursivas que permiten develar su estructura fantasiosa ${ }^{112}$. Pero también pueden manifestarse en el momento

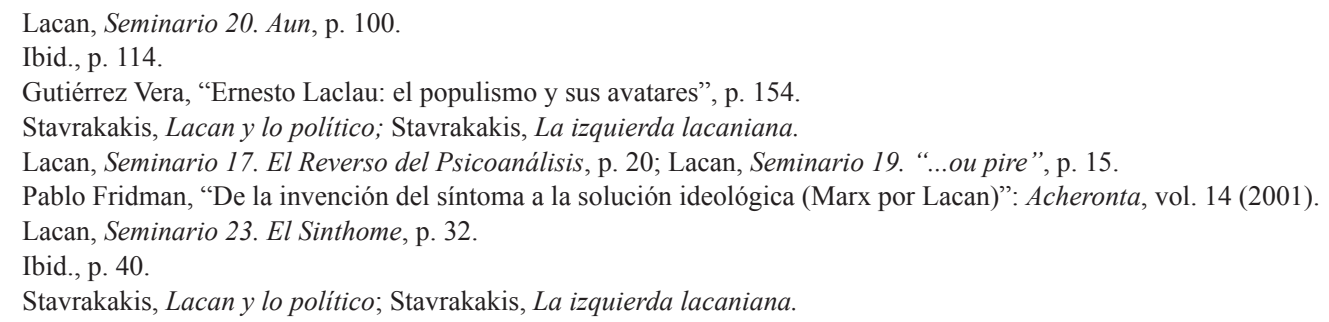


en que determinados agentes de elevada autoridad política atribuida ignoran, menosprecian o dejan de lado determinadas demandas privilegiadas de reconocimiento que estructuran simbólica e imaginariamente las identidades de los sujetos interpelados. Cuando ciertas demandas atribuidas subjetivamente como privilegiadas o muy relevantes son reprimidas (forcluidas) en lo simbólico, retornan en lo Real a través de síntomas que muestran las fallas constitutivas de la realidad imaginaria (fantasmática). Fenoménicamente, la simbolización sintomática frente a los efectos dislocadores ${ }^{113}$ de lo Real puede seguir, contingentemente, dos caminos:

\subsubsection{Inhibición, resignación y apatía política (respuesta pasiva)}

Una primera respuesta de sintomatización simbólica frente a la emergencia de lo Real dislocado se expresa a través de las inhibiciones de los sujetos, que los conducen a la resignación, la pasividad política y la apatía frente a la percepción subjetiva de ausencia de alternativas, o la imposibilidad de transformar activamente la realidad social. Una variante dentro de la respuesta pasiva se relaciona con la noción de angustia. Desde la relectura lacaniana de Freud, la angustia se vincula al temor a perder determinado objeto a causa-de-deseo que se construye como necesario a través del orden significante y genera un circuito de deseo-frustración ${ }^{114}$. Esta concepción permite comprender la angustia social que los sujetos perciben frente a la pérdida del objeto a investido libidinalmente como fetiche imaginario y tapón de la falta.

\subsubsection{Reactivación y acción política (respuesta activa)}

Una segunda respuesta frente al espacio dislocado (lo Real) se manifiesta, desde el orden simbólico, a través de una vía sintomática de reactivación social de tipo activo. El intento de simbolización de lo Real se puede expresar fenoménicamente a partir de dos modalidades:

1. Pasaje al acto: el "pasaje al acto" 115 implica una reacción física violenta del sujeto, centrada en la negatividad destructora. El pasaje al acto se puede manifestar, individual o socialmente, a través de estallidos sintomáticos de violencia anárquica irrefrenable para exteriorizar la bronca acumulada, la sensación de desengaño y desesperanza. En su grado máximo, se expresa a través del acto del suicidio.

2. Atravesamiento simbólico de la fantasía: implica un acto político de procesamiento productivo de lo Real que logra atravesar simbólicamente la fantasía ideológica ${ }^{116}$. El acto de atravesar la fantasía supone un proceso de recomposición fenoménico-discursiva que concluye en la identificación simbólica con el síntoma excluido ${ }^{117}$. Ello implica la aceptación de la falta (\$) y de la alteridad como constitutivas. A diferencia de la modalidad anterior, en este caso el sujeto que emerge sintomáticamente frente al espacio dislocado por lo Real acepta la castración simbólica y estructura, desde el lado de la positividad, un nuevo lazo social barrado (no-todo).

Situado en cierta coyuntura espacio-temporal, el analista del discurso puede examinar en qué medida, en los agentes examinados, el síntoma que emerge de lo Real atraviesa simbólicamente la fantasía ideológica y construye una alternativa política frente al orden dominante, y en qué medida — y con qué intensidad — sólo agrieta parcialmente y/o refuerza el orden vigente.

\subsection{Los modos de simbolizar sintomáticamente lo Real en los acontecimientos históricos catastróficos}

La dinámica del nudo borromeo R.S.I. de Lacan también contribuye a examinar desde el discurso determinados acontecimientos históricos catastróficos que irrumpen inesperadamente y dislocan fuertemente la realidad social. Estos acontecimientos fuertemente disruptivos, como expresiones de la emergencia de lo Real, deben ser analizados a través de sus modos de simbolización subjetiva. En esta línea, los efectos subjetivos de acontecimientos catastróficos y traumáticos, como el atentado en las Torres Gemelas del 11 de septiembre de 2001 en Estados Unidos, la masacre de cuarenta y tres estudiantes en Ayotzinapa (México) del 2014, o el reciente fenómeno del Coronavirus, pueden ser asimilados a hechos sociales intensamente dislocadores que muestran el choque con lo Real-imposible. Este choque con la roca de lo Real desestructura un conjunto de percepciones y significados fuertemente sedimentados y genera efectos subjetivos dislocadores perdurables en el tiempo.

A partir de estas intensas dislocaciones históricas, materializadas a través del orden significante, el analista del discurso puede examinar las percepciones, sensaciones y sentimientos que los sujetos construyen/elaboran retroactivamente para intentar simbolizar el choque con lo Real. Ello permite investigar, de un modo atributivo:

\footnotetext{
13 Laclau, Nuevas reflexiones sobre la revolución de nuestro tiempo.

114 Lacan, Seminario 9. La identificación.

115 Jacques Lacan, Seminario 18. De un discurso que no fuera del semblante, Paidós, Buenos Aires, 2009, p. 32.

116 Žižek, El sublime objeto de la ideología.

117 Stravrakakis, Lacan y lo politico; Stavrakakis, La izquierda lacaniana.
} 
Si frente a la emergencia fuertemente disruptiva de lo Real los sujetos asumen simbólicamente una actitud tendencial de mayor pasividad (naturalización e inhibición, trauma paralizante) o capacidad activatransformadora (disposición a la acción).

Si la actitud tendencialmente activa de los sujetos los conduce a procesar simbólicamente el acontecimiento disruptivo y a reformular ("reactivar") sus ideas sedimentadas a través de acciones sociales (discursivas) fácticas, en qué grado las modifican efectivamente, y cómo se expresan en la dinámica sociopolítica.

\section{Algunas estrategias analíticas útiles para la investigación social}

Desde las premisas básicas de la teoría de la hegemonía, lo social está sobredeterminado por el orden significante, por lo que cualquier objeto, hecho o fenómeno social debe analizarse a través de las construcciones del lenguaje ${ }^{118}$. Para examinar los modos de (des)anudamiento entre lo Real, lo Simbólico y lo Imaginario en la dinámica sociopolítica, el analista del discurso dispone de diferentes técnicas de investigación, que habilitan diversas estrategias metodológicas. Las mismas deben abordarse en función del tema, las preguntas y objetivos de cada investigación.

Una primera alternativa para la investigación social consiste en realizar un análisis más interpretativo de las fantasías, los acontecimientos dislocadores y los síntomas que estructuran discursivamente lo social en determinada coyuntura o proceso político. Una segunda opción consiste en realizar una investigación empíricodiscursiva basada en el uso de fuentes originales. Para ello, el analista político puede proceder a una lectura de síntomas ${ }^{119}$, a través del estudio de las cadenas significantes y el juego de desplazamiento histórico de las metáforas, las metonimias y los puntos nodales que (des)estructuran las fantasías ideológicas. En ambos casos, resulta importante comenzar por una adecuada delimitación espacio-temporal del fenómeno que es objeto de estudio. Para ello, el analista-investigador puede emplear fuentes bibliográficas y de prensa escrita.

Para indagar en las representaciones sociales que construyen los agentes que intentan simbolizar el fenómeno atribuido como traumático en los acontecimientos disruptivos (por ejemplo, un terremoto, una inundación catastrófica, un atentado "terrorista" o la pandemia del Coronavirus), el analista del discurso puede efectuar entrevistas en profundidad, encuestas semi-estructuradas, análisis etnográfico de observación participante y/o grupos focales (focus groups) a sujetos directamente involucradas/os en el acontecimiento y/o a sus seres cercanos (por ejemplo, familiares directos y/o amigas/os). Estas técnicas, en particular las entrevistas semi-estructuradas, permiten profundizar a nivel cualitativo en las vivencias, examinar la intensidad de las evocaciones, sensaciones y sentimientos, e intentar abordar los modos de subjetivación y procesamiento simbólico del fenómeno dislocador ${ }^{120}$. También se pueden analizar textualmente los aspectos emocionales en los discursos oficiales de actores políticos e institucionales claves (por ejemplo, en discursos presidenciales), en archivos de prensa (por ejemplo, diarios de circulación nacional) u otros documentos escritos, y/o trabajar con imágenes y sonidos, a través de fotografías, filmaciones, ilustraciones, dibujos y otros elementos pictóricos y audiovisuales que permiten analizar los aspectos gestuales y corporales de los sujetos, a través de las construcciones del orden significante.

Por ejemplo: Stavrakakis analizó los modos de "simbolización de lo Real" ("ideología verde") y su intento de "dominar lo imposible". Desde América Latina, Ximena Castro-Sardi analizó, a partir de entrevistas, la simbolización traumática del encuentro con lo Real en la masacre de Bojayá (Colombia) del 2002. La autora encontró que los efectos traumáticos se expresaban en los sueños de los familiares y víctimas de la masacre, en sus metáforas crísticas, en sus cantos y en sus demandas de reconocimiento y reparación del daño causado ante el Estado ${ }^{122}$. Verónica Capasso y María Antonia Muñoz ${ }^{123}$ realizaron una investigación sobre los modos de procesar una histórica inundación dislocatoria en la ciudad de La Plata (capital de la Provincia de Buenos Aires) en 2013, a través del análisis de las prácticas discursivas, los textos lingüísticos y las obras de arte que simbolizaron el trauma dislocador y procuraban generar solidaridad y producir una memoria colectiva. Por su parte, Juan Camilo Perdomo Marín ${ }^{124}$ analizó las ceremonias místicas

\footnotetext{
18 Laclau, Nuevas reflexiones sobre la revolución de nuestro tiempo; Laclau y Mouffe, Hegemonía y estrategia socialista.

19 Žižek, El sublime objeto de la ideología.

120 Sobre los usos de estas técnicas en la investigación social, véase en particular las contribuciones de María Eugenia Boito, Claudia Gandía y Adrián Scribano, "Psicoanálisis, psicología e investigación social cualitativa", en Adrián Óscar Scribano (comp.), El proceso de investigación social cualitativo, Prometeo, Buenos Aires, 2008, pp. 223-249.

121 Yannis Stavrakakis, "Fantasía verde y lo Real de la naturaleza: elementos de una crítica lacaniana": Tópicos en educación ambiental, vol. 1 (1999), p. 47.

122 Ximena Castro Sardi, "Invenciones frente a lo Real del trauma o las voces de las víctimas de la masacre de Bojayá, Chocó": Affectio Societatis, vol. 30 (2019), pp. 11-38.

123 Verónica Capasso y María Antonia Muñoz, "Arte después de la inundación. Dos casos de procesamiento de la dislocación después de la catástrofe": Política y Cultura, vol. 45 (2016), pp. 79-98.

124 Juan Camilo Perdomo Marín, La cosmopolítica del yagé, Tesis de Pregrado en Antropología, mimeo, Universidad de Caldas, Colombia, 2016.
} 
del "yagé" en Colombia como un significante tendencialmente vacío, sus imaginarios de plenitud y su goce Real en el cuerpo, a través de la figura del nudo borromeo y herramientas de la teoría lacaniana.

Cabe destacar que el análisis de la estructuración de las fantasías ideológicas y los modos de procesarsimbolizar la dislocación (lo Real) en el síntoma y en los acontecimientos catastróficos, es siempre producto de un análisis hermenéutico-interpretativo del investigador, centrado en los modos de subjetivación del fenómeno.

\section{A modo de conclusión}

En este trabajo exploramos algunos usos innovadores de la figura del nudo borromeo de la teoría lacaniana con el objeto de complejizar y fortalecer el análisis político del discurso en la investigación social. En la primera parte, propusimos tres modalidades de anudamiento borromeico que atan a lo Real, lo Simbólico y lo Imaginario a nivel espacial y temporal. A continuación, distinguimos clases de anudamientos borromeos, e incorporamos un conjunto de variables analíticas útiles para la investigación: la extensión/longitud, la intensidad/fuerza relativa y el tiempo de estructuración y sedimentación social del anudamiento. Luego, abordamos la dinámica discursiva de (des)anudamiento borromeico entre Real, Simbólico e Imaginario, a través del análisis de los modos de identificación imaginarios en las fantasías ideológicas, los acontecimientos catastróficos fuertemente dislocadores y los modos de simbolizar lo Real en el síntoma. En la segunda parte, aportamos algunos recursos analíticos útiles para intentar fortalecer la investigación empírico-discursiva de identidades, fenómenos y procesos políticos y sociales contemporáneos, e ilustramos con algunos ejemplos de estudios previos.

El uso metafórico de la figura del nudo borromeo contiene, además, implicancias epistemológicas relevantes para la investigación social desde la toría política del discurso. Por un lado, contribuye a deconstruir y a superar las lógicas de intelección compartimentales, esencialistas, universalistas, binarias y simplificadoras que predominan en la comunidad científica, para pensar en un campo atravesado por entrecruzamientos e intersecciones múltiples, complejos, transdisciplinarios, éxtimos (al mismo tiempo internos y externos), contingentes, flexibles y cambiantes. Por el otro, contribuye a potenciar la crítica a las fantasías objetivistas, cientificistas y tecnocráticas, que niegan los aspectos simbólicos, inconscientes y subjetivos (identificaciones, afectos, emociones, valores, prejuicios, contradicciones) como constitutivos, rechazan lo Real y creen, de un modo imaginario, que pueden acceder a una realidad objetiva y puramente técnica de lo social. Por último, brinda elementos para desarrollar un nuevo tipo de ciencia compleja que supere la falsa disyunción entre las visiones realistas e idealistas, objetivistas y subjetivistas, a partir de un enfoque de construccionismo social materialista que acepta la falta, el inconsciente, la contingencia, el azar y los límites de lo Real como inherentes.

El uso del nudo borromeo en el APD también contiene implicancias axiológicas para fortalecer la investigación social crítica, desde una izquierda posmarxista. Específicamente, contribuye a potenciar la crítica a las fantasías ideológicas esencialistas, teleológicas y de uniformidad social (desde los fascismos y los fundamentalismos étnicos y religiosos, hasta las ideologías tecnocráticas, mercantilistas y del Fin de la Historia) que niegan la centralidad del orden simbólico en la construcción de lo social, la falta constitutiva, la contingencia radical y el síntoma de lo Real, y, de este modo, rechazan la alteridad, las diferencias particulares y el carácter histórico, precario, fallido y no-todo de lo social.

\section{Referencias bibliográficas}

Álvarez, Alicia, La teoría de los discursos en Jacques Lacan, Letra viva, Buenos Aires, 2006.

Badiou, Alain, Teoría del sujeto, Prometeo, Buenos Aires, 2009.

Blanco, Ana Belén y María Soledad Sánchez, "Hacia una teoría social lacaniana": Miríada, vol. 13 (2017), pp. 171-191.

Boito, María Eugenia, Claudia Gandía y Adrián Óscar Scribano, "Psicoanálisis, psicología e investigación social cualitativa", en Adrián Óscar. Scribano (comp.), El proceso de investigación social cualitativo, Prometeo, Buenos Aires, 2008.

Braunstein, Néstor, El goce. Un concepto lacaniano, Siglo XXI, Buenos Aires, 2006.

Caamaño, Verónica y Silvina Cochia, "Lo que se pluraliza del padre. No sin razón...", IV Congreso Internacional de Investigación y Práctica Profesional en Psicología XIX, Facultad de Psicología, Universidad de Buenos Aires, Buenos Aires, 2012.

Capasso, Verónica y María Antonia Muñoz, “Arte después de la inundación. Dos casos de procesamiento de la dislocación después de la catástrofe": Política y Cultura, vol. 45 (2016), pp. 79-98.

Castro Sardi, Ximena, "Invenciones frente a lo Real del trauma o las voces de las víctimas de la masacre de Bojayá, Chocó": Affectio Societatis, vol. 30 (2019), pp. 11-38.

Eidelsztein, Alfredo, "Por un psicoanálisis no extraterritorial": El rey está desnudo, vol. 1 (2008), pp. 1-30.

Fair, Hernán, "Dislocación, crisis y derrumbe de la hegemonía menemista. De la crisis del Tequila, a las demandas sociales de un orden conservador": Trabajo y Sociedad, vol. 17 (2011), pp. 175-200. 
—, "Contribuciones del psicoanálisis lacaniano a la teoría política y social contemporánea y al análisis sociopolítico crítico": Revista de Ciencias Sociales, vol. 139 (2013), pp. 27-51.

—, "Lo político, la política y las formas de construcción simbólicas e imaginarias del orden social en la teoría de la hegemonía de Ernesto Laclau”: Politeia, vol. 53 (2014), pp. 169-204.

—, "El (no) debate político e ideológico en torno al núcleo nodal de la hegemonía neoliberal en la Argentina": PostData, vol. 19 (2014), pp. 583-635.

-, "Análisis Político del Discurso de Ernesto Laclau: una propuesta para la investigación social transdisciplinaria": Íconos, vol. 54 (2016), pp. 199-226.

Farrán, Roque, "El concepto pensado como nudo borromeo": Žižek Studyies, vol. 3 (2009), pp. 1-23.

- "Badiou y Lacan: algunas consideraciones en torno a lo Real, la ontología y el concepto de sujeto en la práctica filosófica y psicoanalítica": El laberinto de arena, vol. 1, n. ${ }^{\circ} 1$ (2013), pp. 1-28.

—, "El anudamiento complejo de lo político: un análisis de la coyuntura argentina": Identidades, vol. 4 (2013), pp. $22-32$. Fridman, Pablo, "De la invención del síntoma a la solución ideológica (Marx por Lacan)": Acheronta, vol. 14 (2001).

Glynos, Jason y David Howarth, Logics of critical explanation in social and political theory, Routledge, Abingdon, 2007.

Glynos, Jason yYannis Stavrakakis, "Lacan and Political Subjectivity: Fantasy and Enjoyment in Psychoanalysis and Political Theory": Subjectivity, vol. 24 (2008), pp. 256-274.

Gómez, Mariana, “Cuerpo, goce y letra en la última enseñanza de Lacan”: Aesthethika, vol. 2 (2005), pp. 7-24.

Gutiérrez Vera, Daniel, “La textura de lo social”: Revista Mexicana de Sociología, vol. 66 (2004), pp. 311-343.

—, "Ernesto Laclau: el populismo y sus avatares": Íconos, vol. 40 (2011), pp. 151-168.

Lacan, Jacques, "Lo simbólico, lo imaginario y lo real", Conferencia en París, Anfiteatro del Hospital psiquiátrico de Saint Anne, 8 de julio de 1953, Escuela Freudiana de Buenos Aires (EFBA), versión crítica, Buenos Aires, 1953.

—, Seminario 9. La identificación (1961-1962), versión íntegra (en español), Buenos Aires, s.f.

—, Seminario 19. “...ou pire” (1971-1972), versión íntegra (en español), Buenos Aires, s.f.

—, Seminario 21. Los incautos no yerran (Los nombres del padre) (1973-1974), versión íntegra (en español), Buenos Aires, s.f.

—, Seminario 22. R.S.I. (1975-1976), versión íntegra (en español), Buenos Aires, s.f.

-, Seminario 17. El Reverso del Psicoanálisis, Paidós, Buenos Aires, 2006.

—, Seminario 20. Aun, Paidós, Buenos Aires, 2008.

-, Seminario 18. De un discurso que no fuera del semblante, Paidós, Buenos Aires, 2009.

—, Seminario 23. El Sinthome, Paidós, Buenos Aires, 2012.

Laclau, Ernesto, Nuevas reflexiones sobre la revolución de nuestro tiempo, Nueva Visión, Buenos Aires, 1993.

—, "Estructura, historia y lo político", en Judith Butler, Ernesto Laclau y Slavoj Žižek (comps.), Contingencia, hegemonía, universalidad. Diálogos contemporáneos en la izquierda, Fondo de Cultura Económica, México, 2003.

—, La razón populista, Fondo de Cultura Económica, Buenos Aires, 2005.

—, Los fundamentos retóricos de la sociedad, Fondo de Cultura Económica, Buenos Aires, 2014.

Laclau, Ernesto y Chantal Mouffe, Hegemonía y estrategia socialista, Fondo de Cultura Económica, Buenos Aires, 2004.

Lefort, Claude, La invención democrática, Nueva Visión, Buenos Aires, 1990.

Mazzuca, Roberto, Santiago Mazzuca, Marcelo Mazzuca y Carolina Zaffore, "Diferentes lecturas de la noción lacaniana de identificación con el síntoma”: Anuario de Investigaciones, vol. 21 (2014), pp. 93-100.

Murillo, Manuel, "La hipótesis de los tres registros -Simbólico, Imaginario, Real- en la enseñanza de Jacques Lacan": Anuario de Investigaciones, vol. 18 (2011), pp. 123-132.

—, "Versiones del nudo y los anudamientos a partir de lo real, lo simbólico y lo imaginario en Lacan", IV Congreso Internacional de Investigación y Práctica profesional en psicología, Facultad de Psicología, Universidad de Buenos Aires, Buenos Aires, (2012), pp. 545-549.

Parker, Ian y David Pavón Cuellar, Lacan, discurso, acontecimiento, Plaza y Valdés, Madrid, 2013.

Perdomo Marín, Juan Camilo, La cosmopolitica del yagé, Tesis de Pregrado en Antropología, Universidad de Caldas, Colombia, mimeo, 2016.

Rabinovich, Diana, El concepto de objeto en la teoría psicoanalítica, Manantial, Buenos Aires, 2003.

Ramírez Molano, Constanza, “La formación del analista y la excomunión de Lacan”: Nueva Escuela Lacaniana (NEL), vol. 14 (2006).

Schejtman, Fabián y Claudio Godoy, "Dos fases en el uso del nudo borromeo en el último período de la obra de Jacques Lacan": Anuario de Investigaciones, vol. 17 (2010), pp. 133-139.

Stavrakakis, Yannis, "Fantasía verde y lo Real de la naturaleza: elementos de una crítica lacaniana": Tópicos en educación ambiental, vol. 1 (1999), pp. 47-58.

—, Lacan y lo político, Prometeo-UNLP, Buenos Aires, 2007.

—, La izquierda lacaniana, Fondo de Cultura Económica, Buenos Aires, 2010.

Žižek, Slavoj, El sublime objeto de la ideología, Siglo XXI, Buenos Aires, 1992. 